\title{
The Relationship Between Surface Temperature of Building Envelope and Ambient Indoor Temperature for Adobe Brick Building: A Case Study of An Adobe Brick Building in Jos - Nigeria
}

\author{
Ademola Olatunji Jimoh ${ }^{1} \quad$ James Demenongu-Demshakwa $^{1}$ \\ 1. Faculty of Environmental Sciences, Dept. of Architecture University of Jos, Nigeria \\ *E-mail of the corresponding author: ademolajimoh@yahoo.com
}

\begin{abstract}
The study is focused on determining the relationship between surface temperature of building envelope and ambient indoor temperature for non-plastered Adobe Brick building. In this study, data was obtained by measurement of wall surface temperatures internally, externally and the corresponding ambient temperature of spaces enclosed by these walls at given time intervals. A corresponding but non-linear relationship between the three (3) temperature readings was established with the wall surface temperature being cooler across the temperature spectrum recorded. This temperature lag between wall and ambient temperature increases as the day proceeds and reduces at close of day. The ambient indoor temperature level rise from $30.5^{\circ} \mathrm{C}$ min to $38.2^{\circ} \mathrm{C} \max$ between $8: 30 \mathrm{am}-2: 30 \mathrm{pm}$. This is higher than what has been established by previous research for optimal human performance in living spaces. The research recommends insulated interior walls to control heat gain into the ambient space via walls. Externally, soft landscape elements and change of building orientation can be used to regulate the micro climate. The use of mechanical means of temperature control, albeit non-sustainable, might be used as last resort to make these interior spaces more habitable.
\end{abstract}

Keywords: Adobe Bricks, Ambient Temperature, Productivity, Sustainability.

DOI: $10.7176 / \mathrm{JEES} / 10-2-12$

Publication date: February $29^{\text {th }} 2020$

\subsection{Introduction}

Indoor air quality (IAQ) is a major concern to businesses, schools, building managers, tenants, and workers. This is due to the fact that it has significant impact on the health, comfort, well-being, and productivity of the building users. The principal components of indoor air quality are Temperature, Humidity and $\mathrm{CO}_{2}$. However, indoor temperature is considered as important indoor environment factors that affect the comfort and health of humans and it receives most attention from researchers and common people alike. Proper temperature is the basic indoor air requirement and also uniformity of temperatures is important to comfort and efficient living. A study conducted by Seppänen, Fisk, and Lei (2006) shows that performance increases with temperature up to $21-22^{\circ} \mathrm{C}$, and that performance decreases with temperature above $23-24{ }^{\circ} \mathrm{C}$. Another study by Baughman and Arens, (1996) shows that reducing a moderately high classroom temperature in the late summer from the region of $25^{\circ} \mathrm{C}$ to $20^{\circ} \mathrm{C}$ by providing sufficient cooling within space made an improvement in terms of the speed in tasks performance.

Extreme indoor temperatures are a serious health hazard and a too high or low temperature can perceived as unpleasant. Too high a temperature, for instance, exacerbates the effects of insufficient humidity. While too low a temperature, exacerbate the effect of high humidity (Newnum, 2010).

The acceptable, standard or comforting temperature for indoor space will vary widely from region to region. Individual responses can also vary widely as to what they find to be comforting or acceptable to them. According the American society of Heating, Refrigeration and Air Conditioning Engineers, ASHRAE guideline, the recommended temperature value ranges from $20^{\circ} \mathrm{C}$ to $23.3^{\circ} \mathrm{C}$ in the dry season and $22.2^{\circ} \mathrm{C}$ and $26.6^{\circ} \mathrm{C}$ in the summers (ASHRAE, standard 55-2013). However, previous research executed within the same region as this study indicates a comfort range of $24.88^{\circ} \mathrm{C}$ to $27.88^{\circ} \mathrm{C}$ for residential buildings established by Ogbonna \& Harris (2007) for Jos, in Nigeria. Other research indicates a Neutral Temperature as $29.4^{\circ} \mathrm{C}$ for a naturally ventilated office building in Jos Nigeria. This Neutral Temperature of $29.4^{\circ} \mathrm{C}$ falls within the range of the adaptive Psychometric Chart of between $22^{\circ} \mathrm{C}$ to $31^{\circ} \mathrm{C}$ (Jimoh, 2017). 
The efficiency of building enveloping components is dependent on their individual characteristics (reflectivity, absorptivity and emissivity). These components must be able to regulate - in a manner conducive to human habitation - the difference between interior and exterior temperature. For instance, findings by Heathcote 2011, stated that a typical Adobe Earth Wall $300 \mathrm{~mm}$ thick has a thermal resistance of around $0.5 \mathrm{~m} 2 \mathrm{~K} / \mathrm{W}$ or $\mathrm{U}$ value of $2.0 \mathrm{~W} / \mathrm{m} 2 \mathrm{~K}$. While plastered cement/sand sandcrete blocks has a U-value of $0.75-6.53 \mathrm{~W} / \mathrm{m} 2 \mathrm{~K}$. This gives the adobe mud wall an edge over plastered cement/sand sandcrete blocks, which are the dominant walling element for building construction in Nigeria. Russill 2008, however, stated that infilling of modern cement/sand sandcrete blocks can lowers U-value significantly. Goodhew and Griffiths, (2005) posited that un-fired clay bricks with paper, straw or wool cavity insulation have better thermal transmittances of less than $0.35 \mathrm{~W} / \mathrm{m} 2 \mathrm{~K}$ (See Table 1).

Research also shows that increase in the mass contents of the walls of the buildings can improve the thermal comfort of the working space within (Lawal and Ojo, 2011). This research posited that an adobe mud bricks plastered on both surfaces had indoor temperatures below ambient temperature at critical hours compared to Plastered Cement/Sand Sandcrete Blocks. Plastered Cement/Sand Sandcrete Blocks is the predominant enveloping materials for office buildings in this research.

Table 1: Comparison of Wall-Types and Their U-Value

\begin{tabular}{|l|l|l|l|}
\hline S/N & MATERIAL TYPES & U-VALUES & SOURCES \\
\hline 01 & $\begin{array}{l}\text { Clay Bricks With Paper Straw Or Wool } \\
\text { Cavity Insulation }\end{array}$ & $>0.35 \mathrm{~W} / \mathrm{m} 2 \mathrm{~K}$ & Goodhew and Griffiths, 2005. \\
\hline 02 & Light Aggregate Blocks & $0.5 \mathrm{~W} / \mathrm{m} 2 \mathrm{~K}$ & Russill, 2008 \\
\hline 03 & Plastered Cement/Sand Sandcrete Blocks & $\begin{array}{l}0.75-6.53 \\
\mathrm{~W} / \mathrm{m} 2 \mathrm{~K}\end{array}$ & David, 2010 \\
\hline 04 & Dense Blocks & $1.13 \mathrm{~W} / \mathrm{m} 2 \mathrm{~K}$ & Russill, 2008 \\
\hline 05 & $\begin{array}{l}\text { Adobe Mud Bricks Plastered On Both } \\
\text { Surfaces }\end{array}$ & $2.0 \mathrm{~W} / \mathrm{m} 2 \mathrm{~K}$ & Heathcote, 2011 \\
\hline
\end{tabular}

Source: (Adapted from David, 2010., Goodhew \& Griffiths 2005., Heathcote, 2011)

\subsection{Aim of the Study}

The research is aimed at determining the relationship between surface temperature of building envelope and ambient indoor temperature for adobe brick buildings.

\subsection{Methodology of Study}

In weather, ambient temperature refers to the current air temperature - the overall temperature of the outdoor air that surrounds us. Unlike our maximum high and minimum low temperatures, it tells us nothing about what is forecasted. It simply tells what the air temperature is right now, outside our doors. As such, its value constantly changes minute-by-minute. In other words, ambient air temperature is the same thing as "ordinary" air temperature. (Tiffany, 2016). Indoors, ambient temperature is sometimes called room temperature (Zhou and Gong, 2013).

Measurements were taken at hourly intervals between $8.00 \mathrm{hrs}$ and $15.00 \mathrm{hrs}$. This interval represents opening hours and closing hours of the building under study (See Fig 2 and 3). Measurements obtained were outdoor wall surface temperature, indoor wall surface temperature and ambient indoor temperature (See Table 2). The objective data thus collected were presented using simple bar graphs and tables and inferences derived subsequently. The instruments enumerated below were used to obtain objective data as tabulated in Table 2 .

\subsubsection{Temperature Measurements}

In order to consider, the impacts horizontal and vertical variations in temperature within the room, ambient indoor temperature readings were taken at three different locations in each space and at two different levels corresponding to the body level and the ankle level in the offices corresponding to approximately $0.1 \mathrm{~m}$ and $1.2 \mathrm{~m}$ above floor 
levels respectively. An RS 1364 Humidity and Temperature Meter with a thermostat sensor of measuring range: -20 to $60^{\circ} \mathrm{C} ; 0.1^{\circ} \mathrm{C}$ resolution and sampling rate of 2 times per second was used.

\subsubsection{Surface Radiant Temperature}

The measurement of the surface radiant temperature was obtained from the readings of a Cyclops Compac 3 Infrared Thermometer. The infrared System recorded radiant temperatures of external and internal walls surfaces at the body and the ankle level in the building corresponding to approximately $0.1 \mathrm{~m}$ and $1.2 \mathrm{~m}$ above floor levels respectively. A simple average of the readings was adopted as the mean radiant temperature.

\subsubsection{Global Positioning System}

A Cobra GPS 100 global Positioning System receiver was used to obtained global location of buildings of interest. This device provided accurate positioning to within 3 meters, if held in any position open to the sky. It offers information as to current positioning, altitude above sea level, bearing and time of the day.

\subsection{Fieldwork}

The field work consists of obtaining objective data for the purpose of analysis. For easy interpretation, understanding and clarity, the measurements obtained from these instruments above are presented in tables and graphs. There was the need to conduct the instrument data session for all spaces within the building, simultaneously on same day, to ensure integrity and interoperability of data collected.

\subsubsection{Sample Area Characteristics}

Jos, Plateau state is characterized by rocky terrain (topography) giving rises to plateaux and plains, hills and valleys. It enjoys a unique climate (temperate climate) than much of the rest of Nigeria. The University of Jos, located in Jos-North local government area of Plateau State is at an altitude of about 1,217m $(3,993)$ above sea level. The wet season starts from April - October and the dry season starts from November- March. The mean annual rainfall is about $320 \mathrm{~mm}$ in the month of August with an average monthly temperatures ranging from $21^{\circ} \mathrm{C}-25^{\circ} \mathrm{C}\left(70^{\circ} \mathrm{F}-77^{\circ} \mathrm{F}\right)$, and from mid-November to late January, the night time temperatures drop as low as $11^{\circ} \mathrm{C}$ $\left(52^{\circ} \mathrm{F}\right)$. According to (Oniarah 2004). daily solar radiation average of over $4300 \mathrm{wh} / \mathrm{m} 2$ per annum is recorded in Jos annually. The micro-climate within the permanent site of the University is similar to what is obtainable on the Jos-Plateau.

This study was carried within the area identified above. GPS location is given as Lat. $(\mathrm{N}) 9^{0} 58^{\prime} 01.83$ and Long. (E) $8^{0} 52$ ' 21.63. The Adobe Building under study were east-facing and naturally ventilated (NV). The period of study was between $8.00 \mathrm{hrs}$ and $15.00 \mathrm{hrs}$ week days.

\subsubsection{Description of Adobe Brick Building}

The building is in the form of a U-Shape single storey that consists of 14 Shops (See Fig 3). It is characterized by the following futures;

i.The building under study is a U-Shaped, single story adobe brick building consisting of twelve shops with a flat roof.

ii.The building envelope consists of brick walls with fenestration on the North and South walls with a corrugated roofing sheet.

iii. The internal walls of the shops are not rendered and nor painted but the ceiling is painted white (see Fig 2 \& 3).

iv.The North and South sides of the building are characterized by transparent, glazed windows at $900 \mathrm{~mm}$ from the floor level with an open able area of $0.85 \mathrm{~m}^{2}$.

v.The interior of the building is characterized by a well finished floor screed, working surface at $900 \mathrm{~mm}$ from the floor level, fixed around the interior walls and at the middle of the building, right below the window level.

vi.The building has a floor area of $(8100 \mathrm{~mm} \times 2350 \mathrm{~mm})$. 


\subsubsection{Architecture Features of Building Under Study}

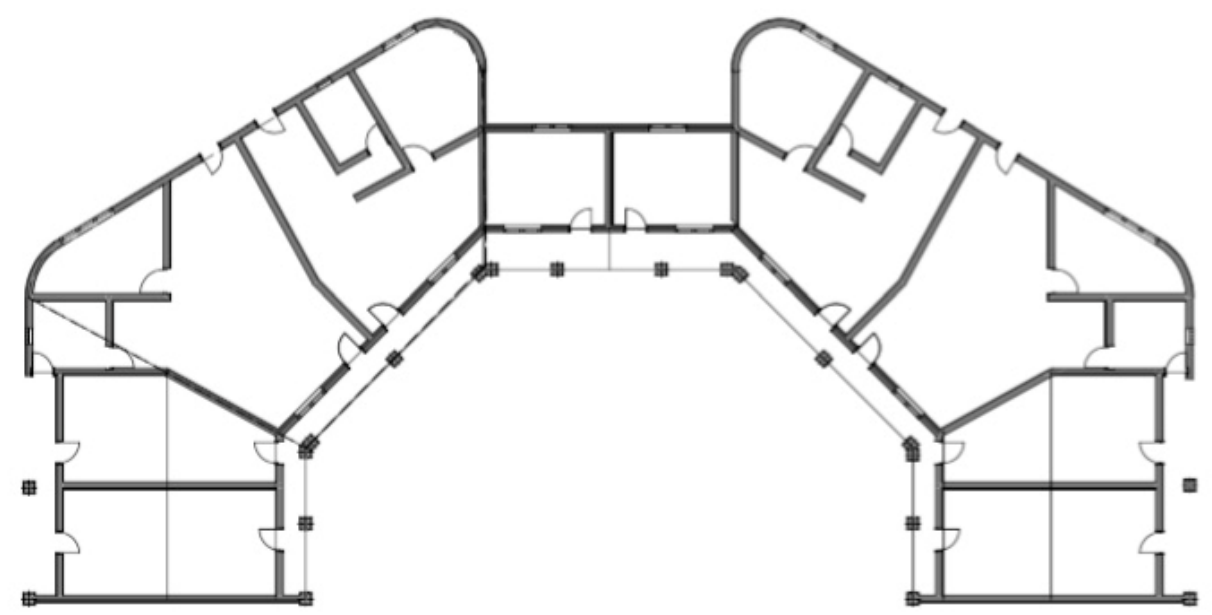

Fig 1 Floor Plan of the Building.

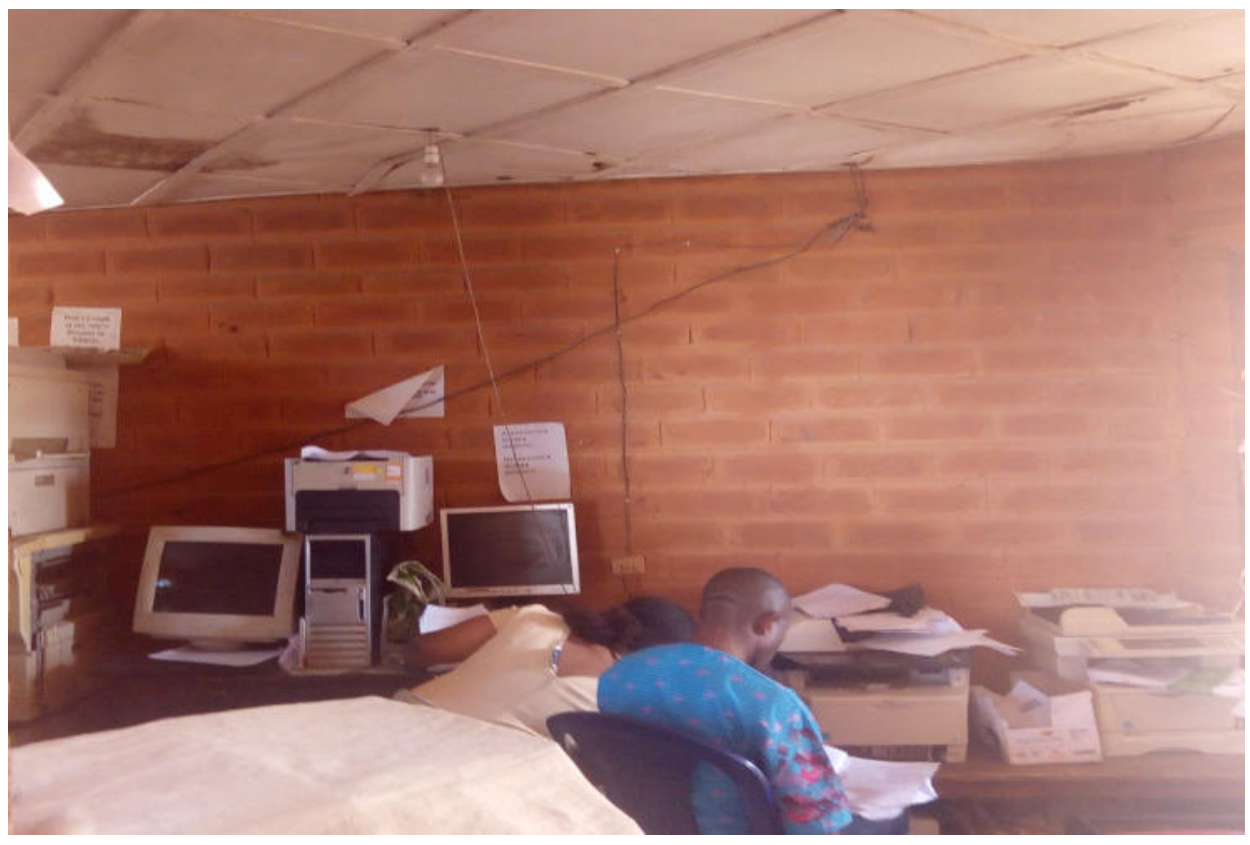

Fig 2 Interior of Building. 


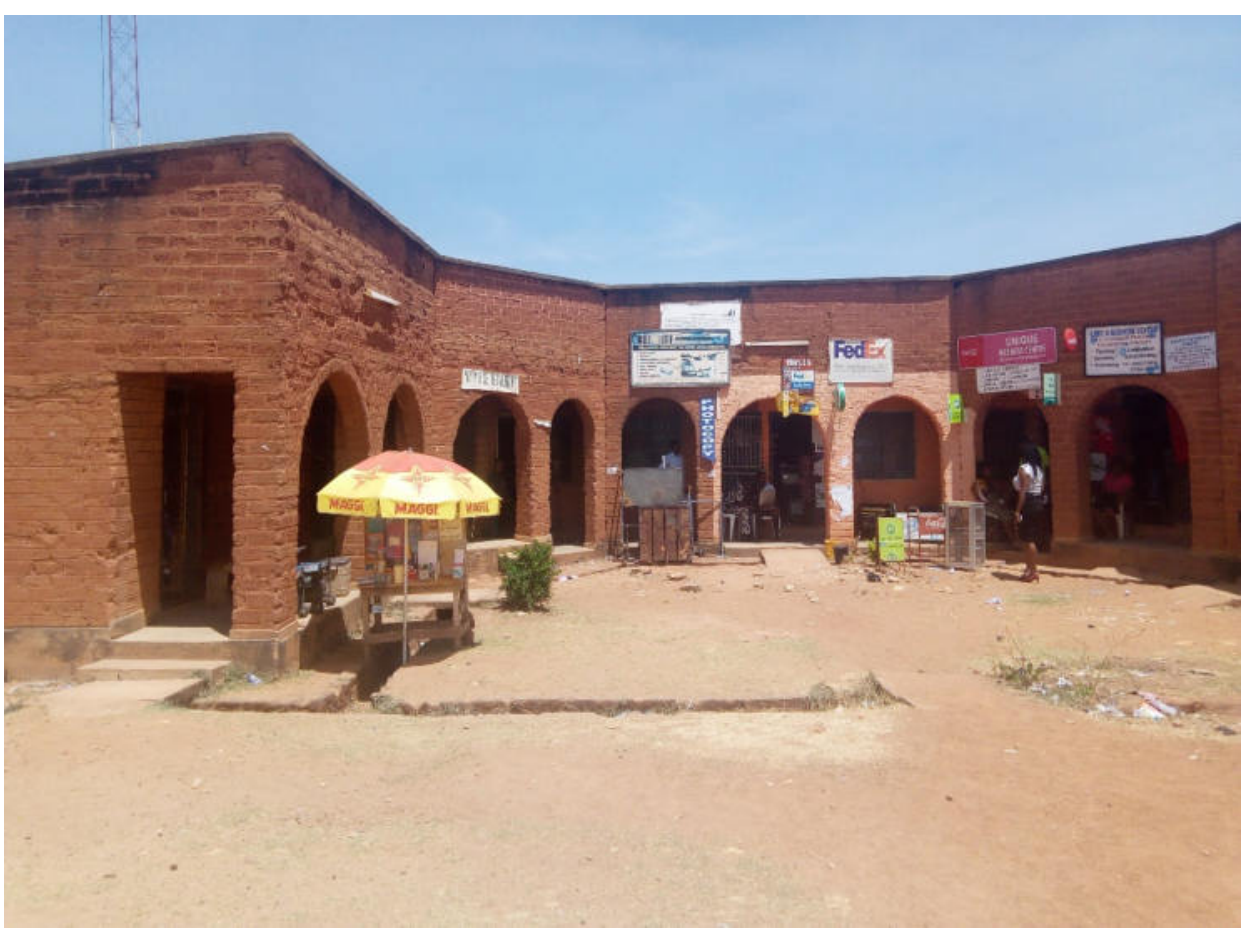

Fig 3 Exterior of building.

\subsubsection{Recorded Environmental Variables}

Table 2: Showing the value of temperature at different Hour from 8:30am - 3:30pm

\begin{tabular}{|l|l|l|l|l|}
\hline TIME & AOT & AIT & IT & OT \\
\hline $8: 30 \mathrm{am}$ & $30.9^{0} \mathrm{c}$ & $30.5^{0} \mathrm{c}$ & $29.5^{0} \mathrm{c}$ & $27.5^{0} \mathrm{c}$ \\
\hline $9: 30 \mathrm{am}$ & $33.0^{0} \mathrm{c}$ & $32.8^{0} \mathrm{c}$ & $28.5^{0} \mathrm{c}$ & $29.0^{0} \mathrm{c}$ \\
\hline $10: 30 \mathrm{am}$ & $36.6^{0} \mathrm{c}$ & $33.4^{0} \mathrm{c}$ & $28.3^{0} \mathrm{c}$ & $30.4^{0} \mathrm{c}$ \\
\hline $11: 30 \mathrm{am}$ & $38.7^{0} \mathrm{c}$ & $35.6^{0} \mathrm{c}$ & $30.4^{0} \mathrm{c}$ & $32.3^{0} \mathrm{c}$ \\
\hline $12: 30 \mathrm{pm}$ & $39.9^{0} \mathrm{c}$ & $36.8^{0} \mathrm{c}$ & $31.5^{0} \mathrm{c}$ & $35.5^{0} \mathrm{c}$ \\
\hline $1: 30 \mathrm{pm}$ & $38.5^{0} \mathrm{c}$ & $36.6^{0} \mathrm{c}$ & $32.5^{0} \mathrm{c}$ & $36.0^{0} \mathrm{c}$ \\
\hline $2: 30 \mathrm{pm}$ & $40.8^{0} \mathrm{c}$ & $38.2^{0} \mathrm{c}$ & $34.5^{0} \mathrm{c}$ & $38.5^{0} \mathrm{c}$ \\
\hline $3: 30 \mathrm{pm}$ & $38.4^{0} \mathrm{c}$ & $35.6^{0} \mathrm{c}$ & $33.5^{0} \mathrm{c}$ & $38.0^{0} \mathrm{c}$ \\
\hline
\end{tabular}

Source: Author's Survey

Where:

AOT $=$ Ambient Outdoor Temperature

$\mathrm{AIT}=$ Ambient Indoor Temperature

IT $=$ Inner Wall Surface Temperature

OT $=$ Outer Wall Surface Temperature 


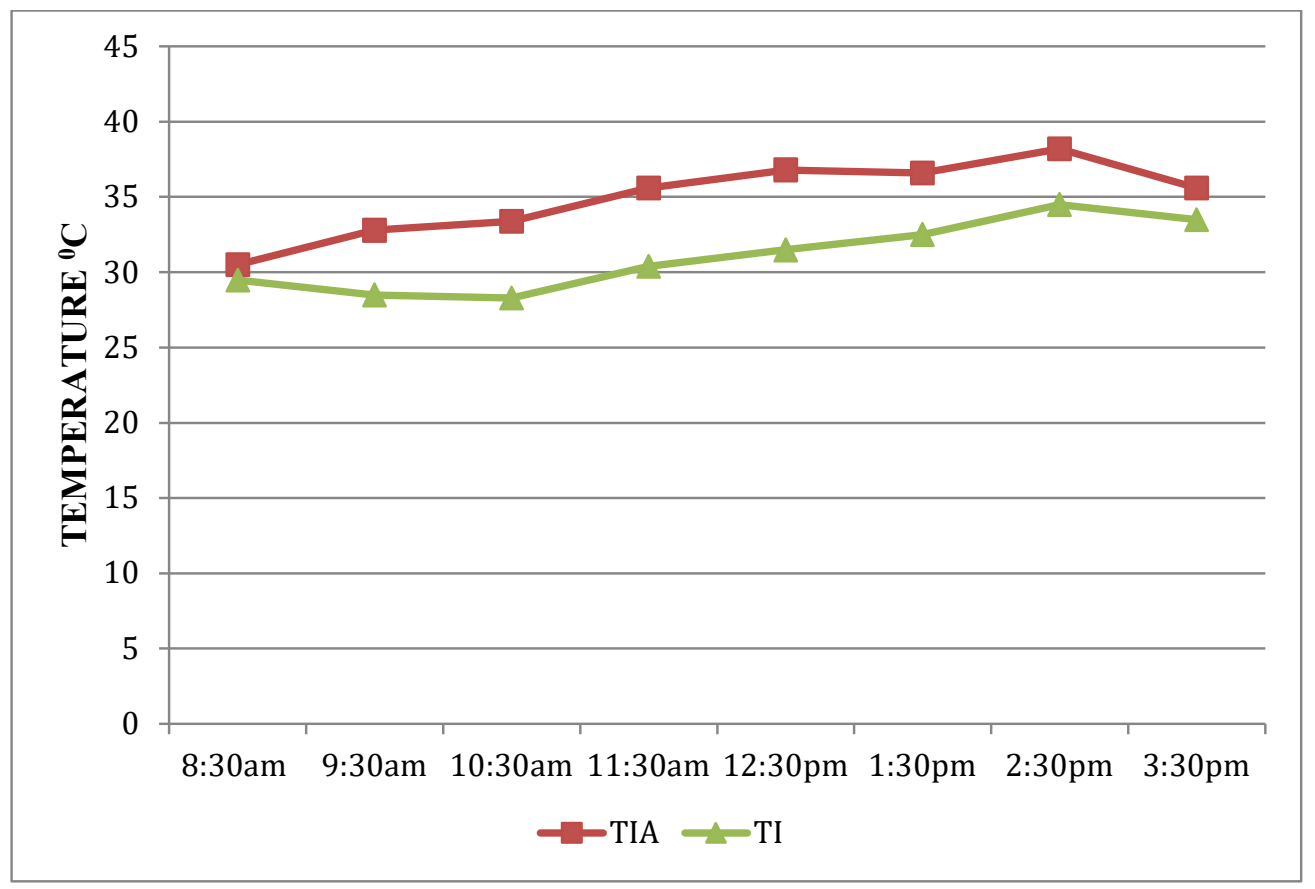

FIG. 4 The Relationship Between Inside Wall And Inside Ambient Temperature From 8:30am - 3:30pm

Where:

AIT $=$ Ambient Indoor Temperature

IT= Inner Wall Surface Temperature

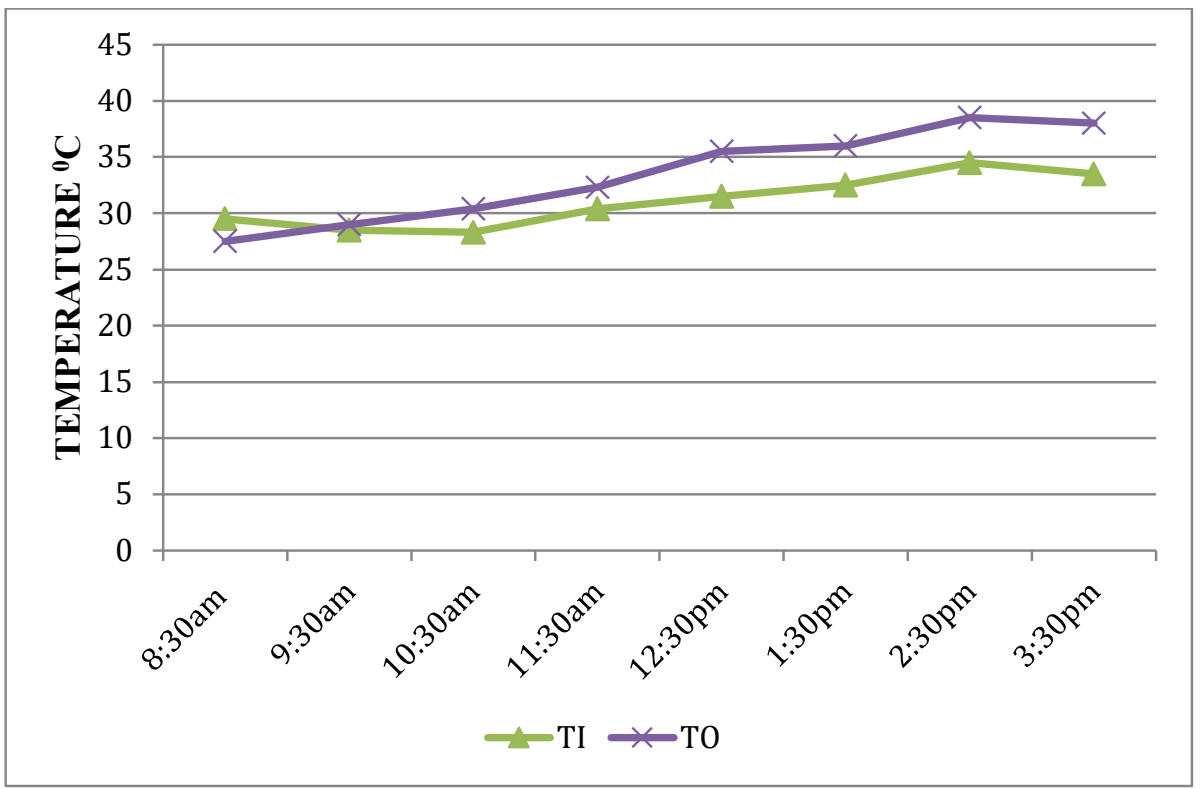

FIG 5 The Relationship Between Outside Wall And Inside Wall Temperature From 8:30am - 3:30pm

Where:

$\mathrm{TI}=$ Temperature Inner Wall

$\mathrm{TO}=$ Temperature Outer Wall 


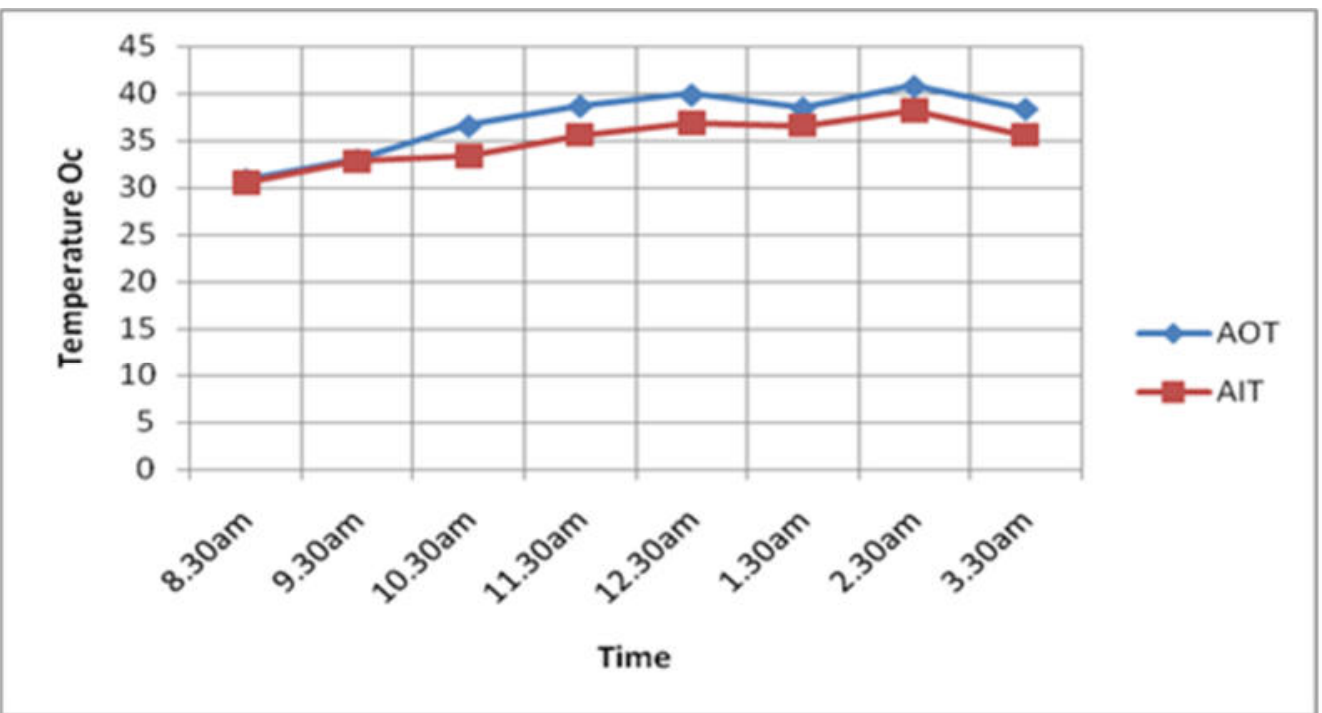

FIG 6 The Relationship Between Outdoor And Indoor Ambient Temperature From 8:30am - 3:30pm

Where:

AOT $=$ Ambient Outdoor Temperature

AIT $=$ Ambient Indoor Temperature

\subsection{Analysis of Findings}

There are slight fluctuations in all temperature readings measured, but there is a general increase in temperature as the day progresses for all surfaces and spaces. Inner wall temperature is general observed to be cooler than ambient indoor temperature and is the coolest for all temperature measured (See Fig 4). This has a cooling effect on the interior spaces and so requiring less mechanical cooling load on the building. This is due to the higher UValue of the walling materials as earlier explained (See Table 1).

At the start of the day, the outer wall surface temperature is cooler than the internal wall surface temperature. As the day progresses, the inner wall temperature becomes cooler (See Fig 5). The inherent thermal properties of the walling materials ensure cooler interior temperatures. Here, the walling material properties ensure the difference between ambient interior and exterior surface temperatures are minimal throughout the range of temperature measured (See Fig 6). However, the ambient interior temperature falls within $30.5^{\circ} \mathrm{C}$ to $38.2^{\circ} \mathrm{C}$. This is beyond the acceptable temperature as defined by previous researchers (See Ogbonna \& Harris 2007 and Jimoh, 2017).

\subsection{Conclusion}

As earlier enumerated, the virtues of using adobe bricks as walling are numerous in the context of temperature control. This is due to the excellent U-Value of this material. However, these virtues must be complemented by appropriate design parameters such adequate fenestration, building orientation and appropriate landscaping. These design elements must work in conjunction with the inherent walling properties so as to ensure a livable and functional interior space.

\subsection{Recommendation}

Temperature is considered as an indoor environmental factor that affects human comfort. The rise in ambient interior temperature tends to create discomfort within the building envelope; efforts should be made to mitigate this negative influence in functional spaces so as to maximize the function it was design for. These measures are thus recommended:

i. Cladding the exterior wall surfaces with insulating materials or other finishes, which will lag the wall against heat and reduce heat gain into the interior space of the building should be considered. 
ii. Provision of larger window openings is also recommended as research has shown its benefit to comfortable interior spaces as this can be achieved with a larger window area to total indoor volume. (Jimoh and Ogunrayewa 2015).

iii. Reducing the temperature of the microclimate around the building with the introduction of landscaping element (soft) such as trees, shrubs and lawns, which will stabilize and reduce temperature of the surrounding environment.

iv. The use of mechanical means to regulate the temperature by increase in air movement, thereby increasing the level of comfort of occupants/ user.

v. Climate, weather condition and building envelope type varies. The research recommends the execution of similar research in different geographical region on building with similar walling types. This will grant further depth into the understanding of the relationship between walling components and interior comfort in terms of ambient temperature.

\subsection{References}

ASHRAE Standard 55: Thermal Environmental Conditions for Human Occupancy; ASHRAE: Atlanta, GA, USA, (2010).

Baughman, A., \& Arens, E., (1996). Indoor Humidity and Human Health - Part I: Literature Review of Health Effects of Humidity- Influenced Indoor Pollutants. ASHRAE Transactions, Vol. 102, Pt. 1, pp. 193-211

David, A. (2010). The thermal conductivity and cold crushing strength of locally produced sandcrete bricks of different compositions of sawdust, palm-nut fibre and pozzolana incorporated - A search for room comfort in the tropics. (Unpublished Manuscript). Kwame Nkrumah University of Science and Technology.

Goodhew, S., \& Griffiths, R. (2005). Sustainable earth walls to meet the building regulations. Science Direct. Energy and Buildings, 37, 451-459. Retrieved from http:/www.sciencedirect.com.

Heathcote, K. (2011). The thermal performance of earth buildings. Informes de la Construcción, 63(523), $117-$ 126.

Jimoh, A.O. (2017) “An Assessment of Energy Performance of Administrative Buildings in Jos, Nigeria". Unpublished Ph.D. Dissertation; University of Jos, Nigeria.

Jimoh, A.O \& Ogunrayewa, M.O. (2015) Evaluation of Co2 Levels as a Function of Window Area and Total Room Volume Ratio for Office Buildings in Jos, Nigeria. Asian Academic Research Journal of MultiDisciplinary. Vol.1, Issue 32 (April 2015) ISSN: 2319-2801, pp.108-126.

Lawal, A.F., Ojo, O. J. (2011). Assessment of thermal performance of residential buildings in Ibadan land, Nigeria. Journal of Emerging Trends in Engineering and Applied Sciences (JETEAS), 2(4), 581-586. Retrieved from http:// jeteas.scholarlink research.org.

Newnum, D. (2010). The effects of relative humidity on respirator performance, Justin University of Iowa. Retrieved from http://ir.uiowa.edu/etd/861.

Ogbonna, A.C., \& Harris, D.J. (2007). Thermal comfort in Sub-Saharan Africa: Field research report in Jos, Nigeria. School of the Built Environment Heriot Watt University. Retrieved from http://www.sciencedirect.com

Oniarah, A. (2004). Nigerian meteorological agency Clips focal point July, 2004 weather reports. Retrieved from http://www.wmo.ch/pages/prog/wcp/wcasp/clips/fp.

Tiffany, M. (2016). High and Low temperature. Tom S, (2009) the relationship between relative humidity, temperature and dew point. Retrieved from www.chicagotribune.com

Zhou, Y. and Gong, G., (2013). Energy Analysis of The Building Heating and Cooling System from The Power Plant to The Building Envelop with Hourly Variable Reference State. Energy and Buildings, 56, pp. 94-99. 